\title{
Association between the TP53 codon 72 polymorphism and risk of oral squamous cell carcinoma in Asians: a meta-analysis
}

\author{
Xian-Tao Zeng ${ }^{1 \dagger}$, Wei Luo ${ }^{2 \dagger}$, Pei-Liang Geng ${ }^{3}$, Yi Guo ${ }^{4}$, Yu-Ming Niu ${ }^{1}$ and Wei-Dong Leng ${ }^{\text {* }}$
}

\begin{abstract}
Background: Several epidemiological studies have previously investigated the association between the TP53 codon 72 polymorphism and oral squamous cell carcinoma (OSCC) susceptibility; however, current results are inconsistent. We therefore performed this meta-analysis to thoroughly investigate any association among Asian patients.

Methods: A comprehensive search of PubMed and Embase databases was performed up to December 2013. We only considered studies consisting of patients diagnosed with OSCC by pathological methods. Statistical analyses were performed using Review Manager (RevMan) 5.2 software and odds ratios (ORs) with 95\% confidence intervals (Cls) were used to assess the association.
\end{abstract}

Results: A total of 11 case-control studies involving 2,298 OSCC patients and 2,111 controls were included. We found no association between the TP53 codon 72 polymorphism and OSCC susceptibility $[(\mathrm{OR}=0.77,95 \% \mathrm{Cl}=0.48-1.22)$ for $\mathrm{Arg}$ vs. Pro; $(\mathrm{OR}=0.67,95 \% \mathrm{Cl}=0.31-1.43)$ ArgArg vs. ProPro; $(\mathrm{OR}=1.14,95 \% \mathrm{Cl}=0.97-1.35)$ ArgPro vs. ProPro; $(\mathrm{OR}=0.85,95 \%$ $\mathrm{Cl}=0.53-1.34)$ (ArgPro + ArgArg) vs. ProPro; or $(\mathrm{OR}=0.34,95 \% \mathrm{Cl}=0.34-1.23)$ for ArgArg vs. (ProPro + ArgPro)]. However, subgroup analysis demonstrated an association between the TP53 codon 72 polymorphism and human papillomavirus (HPV)-related OSCC patients. Although statistical heterogeneity was detected, there was no evidence of publication bias.

Conclusions: Current results suggest that the TP53 codon 72 polymorphism is not associated with OSCC in Asians without the presence of HPV infection. Further research is necessary to determine if such a relationship exists in HPV-related OSCC patients.

Keywords: TP53 rs1042522, TP53 codon 72 polymorphism, Oral squamous cell carcinoma, Human papillomavirus, Meta-analysis

\section{Background}

Oral cancer is ranked as the 11th most common type of cancer worldwide [1], with a higher prevalence in South and Southeast Asian countries such as India, Bangladesh, China, and Sri Lanka [2]. Oral squamous cell carcinoma (OSCC) originates from the squamous cells that cover the surface of the mouth and is a major type of oral cancer, accounting for more than $90 \%$ of cases [3]. Tobacco use (chewing with or without smoking), alcohol consumption, and human papillomavirus (HPV) infection are important

\footnotetext{
*Correspondence: lengtaihe@163.com

${ }^{\dagger}$ Equal contributors

'Department of Stomatology and Center for Evidence-Based Medicine and Clinical Research, Taihe Hospital, Hubei University of Medicine, Shiyan 442000, P.R. China

Full list of author information is available at the end of the article
}

risk factors for development of OSCC $[4,5]$; however, molecular mechanisms relating to OSCC are still being investigated, while genetic predisposition is gaining increasing attention [6-8].

The tumor protein p53 (TP53) gene, located on chromosome $17 \mathrm{p} 13$, is one of the most frequently mutated genes in human cancers and has been reported to be a significant determining factor in carcinogenesis [9]. The codon 72 polymorphism (rs1042522) is located in exon 4 of TP53 gene, and involves a CCC $\rightarrow$ CGC transition leading to a proline (Pro) $\rightarrow$ arginine (Arg) amino acid substitution at position 72 (Pro72Arg) (http://www. ncbi.nlm.nih.gov/snp/?term=rs1042522) [10]. Many published meta-analyses have indicated that the TP53 codon 72 polymorphism might be associated with increased 


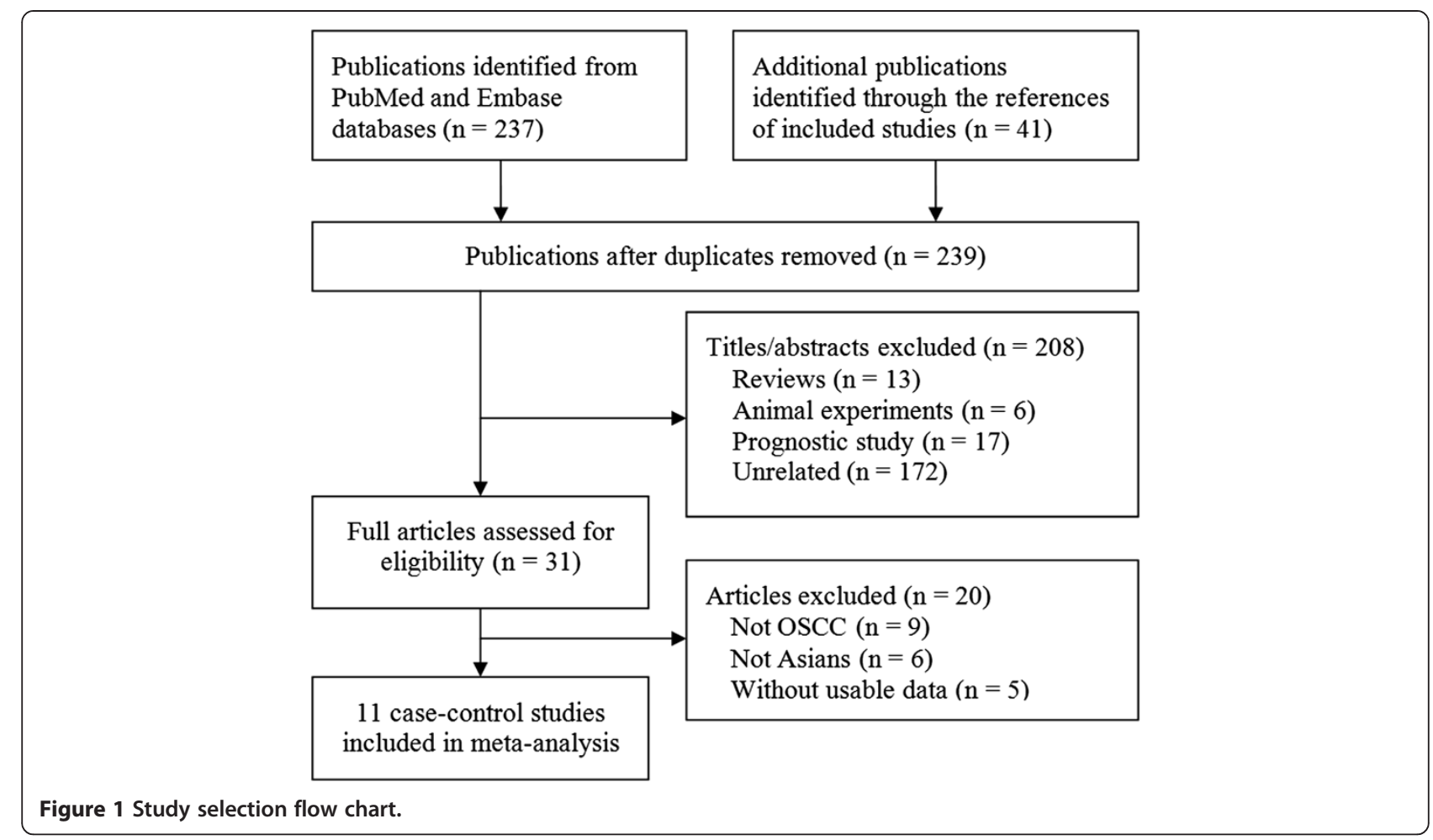

susceptibility to cervical cancer [11], bladder cancer [12], and nasopharyngeal carcinoma [13].

Several previous studies have explored the association between the TP53 codon 72 polymorphism and OSCC susceptibility; however, existing results are inconsistent. In 2009, Zhuo et al. performed a meta-analysis of nine case-control studies and found that the TP53 codon 72 polymorphism might be a risk factor for oral carcinoma [14]. This is in agreement with another meta-analysis of 17 case-control studies by Jiang et al. published in 2013 [15]. Both meta-analyses included patients with OSCC but did not stratify the condition as a separate subgroup $[14,15]$. Additionally, several more recent studies have since been published. Therefore, we conducted this metaanalysis to obtain accurate and up-to-date estimates of the association between the TP53 codon 72 polymorphism and OSCC susceptibility in Asians. Subgroup analysis was also performed to investigate any potential HPV-specific effects.

\section{Methods}

This meta-analysis adheres to the recommended Preferred Reporting Items for Systematic Reviews and Meta-Analyses (PRISMA) guidelines [16].

\section{Inclusion criteria}

We included case-control studies that met the following eligibility criteria: (1) evaluated the association between the TP53 codon 72 polymorphism and OSCC susceptibility in
Asians; (2) included OSCC cases diagnosed by histologic methods or clearly reported the type, and contained healthy or cancer-free controls; (3) provided the number of individual genotypes in both the case and control groups, or enabled the genotypes to be calculated from available published data; (4) published in English or Chinese; and (5) used genotyping was polymerase chain reaction (PCR) including PCR- polymerase chain reactionrestriction fragment length polymorphism (RFLP) and PCR- polymerase chain reaction-single strand conformation polymorphism (SSCP) for genotyping.

\section{Search strategy}

We searched PubMed and Embase databases up to December 10, 2013 with the following search items: [(oral OR tongue OR mouth) AND (cancer OR carcinoma) AND (p53 OR TP53) AND polymorphism]. Reference lists of the included studies and published meta-analyses on related topics were also screened for additional studies.

\section{Data extraction}

Two authors independently extracted the following trial data from included studies: last name of the first author, publication year, countries of origin, HPV status of cases, source of control, number and genotyping distribution of cases and controls, diagnostic method for OSCC, genotyping method, and Hardy-Weinberg Equilibrium (HWE) for controls [17]. Disagreements were resolved by discussion. 


\section{Table 1 Characteristics of included studies}

\begin{tabular}{|c|c|c|c|c|c|c|c|c|c|c|c|c|c|c|}
\hline \multirow[t]{2}{*}{ Reference } & \multirow[t]{2}{*}{ Country } & \multicolumn{5}{|c|}{ oscc } & \multirow{2}{*}{$\begin{array}{l}\text { Diagnostic } \\
\text { method }\end{array}$} & \multirow{2}{*}{$\begin{array}{l}\text { Source of } \\
\text { control }\end{array}$} & \multicolumn{4}{|c|}{ Control } & \multirow{2}{*}{$\begin{array}{l}\text { Genotype } \\
\text { method }\end{array}$} & \multirow[t]{2}{*}{ HWE } \\
\hline & & HPV & Total & ProPro & ArgPro & ArgArg & & & Total & ProPro & ArgPro & ArgArg & & \\
\hline Tandle 2001 [19] & India & No & 72 & 14 & 52 & 6 & Histopathological & PB & 153 & 31 & 100 & 22 & PCR & $<0.001$ \\
\hline Nagpal 2002 [20] & India & Yes & 110 & 21 & 58 & 31 & Histological & PB & 26 & 2 & 11 & 13 & PCR & 0.876 \\
\hline Kietthubthew 2003 [21] & Thailand & No & 97 & 21 & 44 & 32 & Histological & PB & 97 & 28 & 34 & 35 & PCR & 0.004 \\
\hline Hsieh 2005 [22] & China & No & 629 & 114 & 328 & 187 & Histological & PB & 371 & 66 & 177 & 128 & PCR-RFLP & 0.723 \\
\hline Kuroda 2007 [24] & Japan & No & 100 & 15 & 44 & 41 & Histological & $\mathrm{HB}$ & 271 & 45 & 117 & 109 & PCR-RFLP & 0.159 \\
\hline Bau 2007 [23] & China & No & 137 & 21 & 70 & 46 & NA & $\mathrm{HB}$ & 105 & 22 & 65 & 18 & $P C R$ & 0.139 \\
\hline Lin 2008 [25] & China & No & 297 & 46 & 155 & 96 & Histological & PB & 280 & 52 & 156 & 72 & PCR-RFLP & 0.085 \\
\hline Tu 2008 [26] & China & No & 189 & 30 & 106 & 53 & NA & $\mathrm{HB}$ & 116 & 15 & 60 & 41 & PCR & 0.337 \\
\hline Misra 2009 [27] & India & No & 308 & 66 & 155 & 87 & Histopathological & $\mathrm{HB}$ & 342 & 98 & 159 & 85 & $P C R$ & 0.203 \\
\hline Saini 2011 [28] & Malaysia & Yes & 99 & 37 & 40 & 22 & NA & $\mathrm{HB}$ & 90 & 23 & 39 & 28 & PCR & 0.215 \\
\hline Saleem 2013 [29] & Pakistan & No & 260 & 125 & 113 & 22 & NA & PB & 260 & 33 & 23 & 204 & PCR-SSCP & $<0.001$ \\
\hline
\end{tabular}

OSCC, oral squamonus cell carcinoma; HPV, human papillomavirus; NA, not available; HB, hospital-based; PB, population-based; HWE, Hardy Weinberg Equilibrium. 


\section{Statistical analysis}

We employed the fixed-effect analytical model first to pool results of the included studies, and the $I^{2}$ statistic [18] was used to test for statistical heterogeneity. If $I^{2}$ was more than $40 \%$, we switched to a random-effects model. The odds ratios (ORs) and relevant 95\% confidence intervals (CIs) were used to quantify the strength of association between the TP53 codon 72 polymorphism and OSCC susceptibility using five genetic models: Arg vs. Pro, ArgArg vs. ProPro, ArgPro vs. ProPro, (ArgPro + ArgArg) vs. ProPro, and ArgArg vs. (ProPro + ArgPro). Additionally, subgroups analyses based on HPV status, source of controls, and HWE status for controls were performed. Publication bias was detected by examination of funnel plots. All statistical analyses were conducted using Review Manager (RevMan) software (version 5.2 for Windows).

\section{Results}

\section{Study characteristics}

Our systematic literature search identified 278 studies that met the inclusion criteria. After deduplication and exclusion of the clearly irrelevant studies, we eventually included 11 case-control studies [19-29] involving 2,298 OSCC patients and 2,111 controls. Figure 1 shows the study selection process. Of the 11 included studies, two recruited OSCC patients with HPV [20,28], and three enrolled patients with disrupted HWE $[19,21,29]$. Baseline characteristics of the 11 studies are summarized in Table 1.

\section{Meta-analysis}

Table 2 illustrates results of the overall and subgroup analyses. Overall, there was no association between the TP53 codon 72 polymorphism and OSCC susceptibility in Asians $[(\mathrm{OR}=0.77,95 \% \mathrm{CI}=0.48-1.22)$ for Arg vs. Pro; $(\mathrm{OR}=0.67,95 \% \mathrm{CI}=0.31-1.43)$ for ArgArg vs. ProPro; $(\mathrm{OR}=1.14,95 \% \mathrm{CI}=0.97-1.35)$ for ArgPro vs. ProPro, Figure 2; $(\mathrm{OR}=0.85,95 \% \mathrm{CI}=0.53-1.34)$ for (ArgPro +
ArgArg) vs. ProPro; and $(\mathrm{OR}=0.34,95 \% \mathrm{CI}=0.34-1.23)$ for ArgArg vs. (ProPro + ArgPro)].

Results of the subgroup analyses stratified by source of controls and HWE status for controls were similar to those of the overall analyses. However, when stratified by HPV status, a correlation between the TP53 codon 72 polymorphism and HPV infection was observed (Table 2).

\section{Publication bias}

A funnel plot based on the ArgPro vs. ProPro genetic model showed a relatively symmetrical distribution, enabling us to conclude that there was no publication bias (Figure 3).

\section{Discussion}

Arg and Pro are two distinct functional alleles that are encoded by the TP53 codon 72, and Pro to Arg is the most informative polymorphism in the TP53 gene and have been found to be associated with human cancers $[10,30]$. Among the published meta-analyses exploring the association between this polymorphism and cancers, some revealed an increased susceptibility of disease [11-13], while others failed to find any association [31-33]. Results from these meta-analyses indicate an interesting phenomenon, which is that different metaanalyses of the same cancer type could yield opposite results. Although two meta-analyses investigating the relationship of the TP53 codon 72 polymorphism and oral cancer susceptibility both reached the same conclusions [14,15], such association among the Asian population is unclear. Given that OSCC has a high incidence in this population, we conducted the current meta-analysis to further investigate if the TP53 codon 72 polymorphism plays a role in the development of OSCC.

A total of 2,298 OSCC patients and 2,111 controls were included in our meta-analysis. Results of the overall

Table 2 Overall and subgroups meta-analysis of TP53 codon 72 polymorphism and OSCC risk in Asians

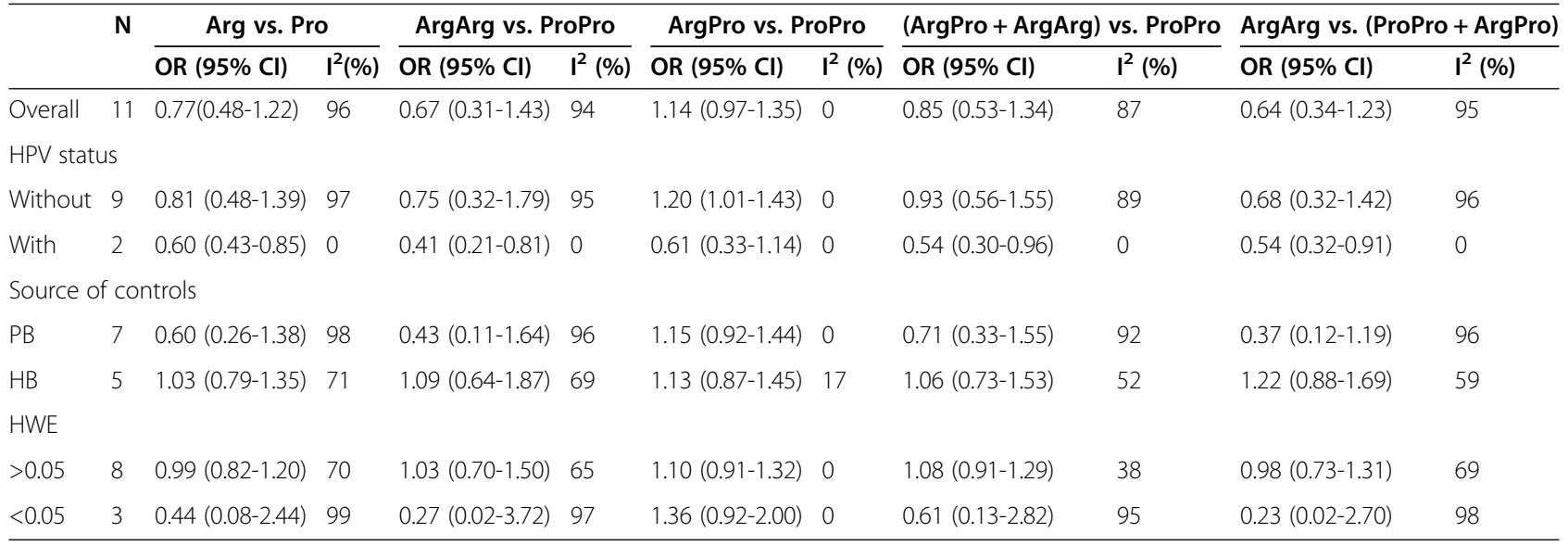

OSCC, oral squamonus cell carcinoma; HPV, human papillomavirus; $\mathrm{HB}$, hospital-based; PB, population-based; HWE, Hardy Weinberg Equilibrium. 


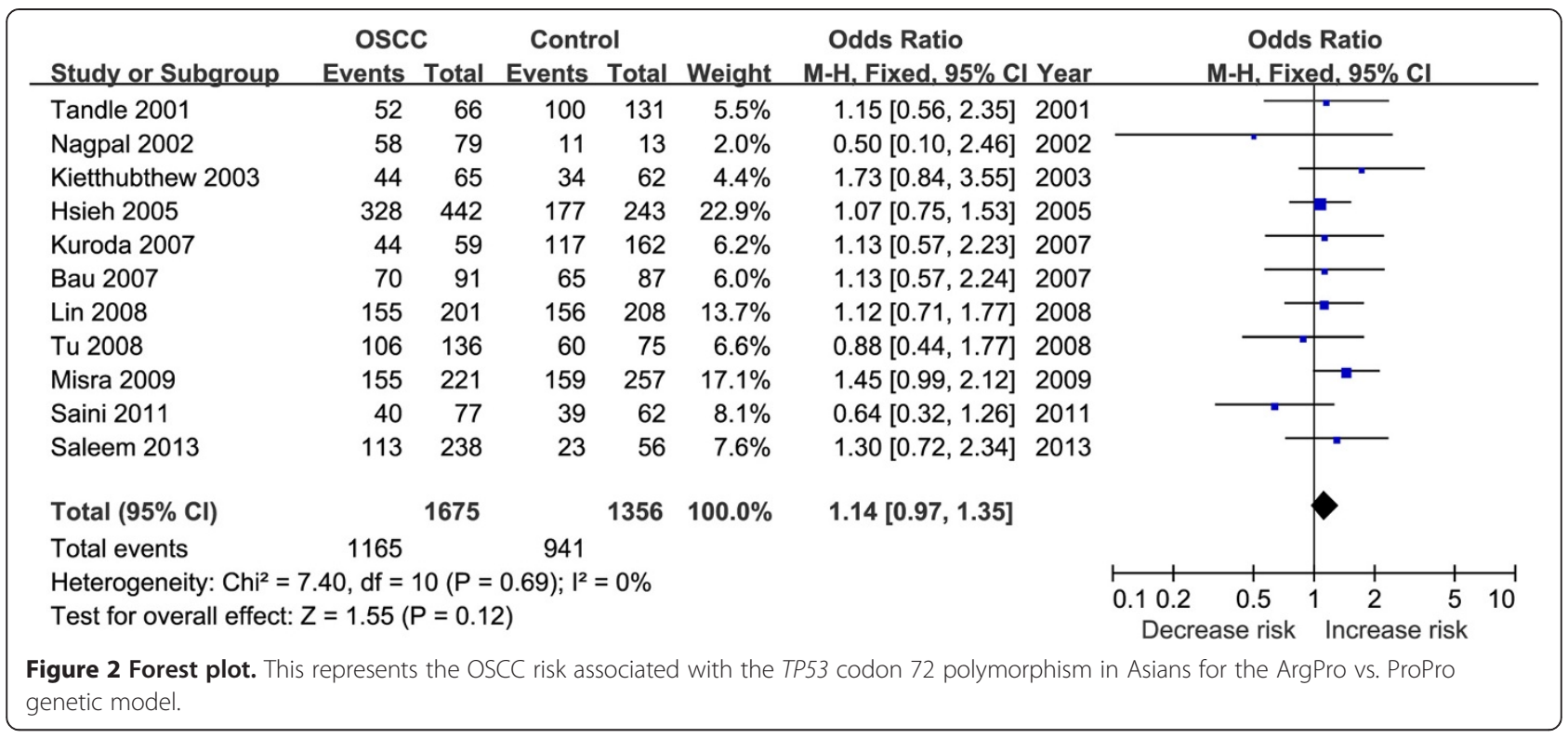

population demonstrated a negative association of the TP53 codon 72 polymorphism and OSCC, although subgroup analysis revealed a positive correlation between the polymorphism and HPV status in OSCC patients. Our results are in contrast with those reported by Zhou et al. [14], which was based on three studies reporting HPV infection status; however, only one of these focused on an Asian population [20]. Moreover, this earlier meta-analysis is limited by its small sample size and mixed ethnicity. In contrast to the two previous meta-analyses [14,15], our meta-analysis only focused on OSCC in Asians.

The relationship between HPV and OSCC has been previously established [34]. Our meta-analysis also found that the TP53 codon 72 polymorphism was associated with HPV-related OSCC susceptibility cases. However, because there is no association between this polymorphism and non-HPV OSCC cases, it is currently unclear whether the polymorphism is merely a marker of HPV-related OSCC. Further research is warranted to investigate this relationship.

In 2011, Heah et al. found a significant correlation between p53 expression and TP53 aberration in 26 OSCC cases [35]. This finding is in contrast to the results of our present meta-analysis, although it should be noted that TP53 contains multiple polymorphisms in addition to the one in codon 72 .

Our meta-analysis has a number of limitations. First, like all meta-analyses, it is a secondary retrospective study that is limited by various factors including quality of the original studies, study population differences, and

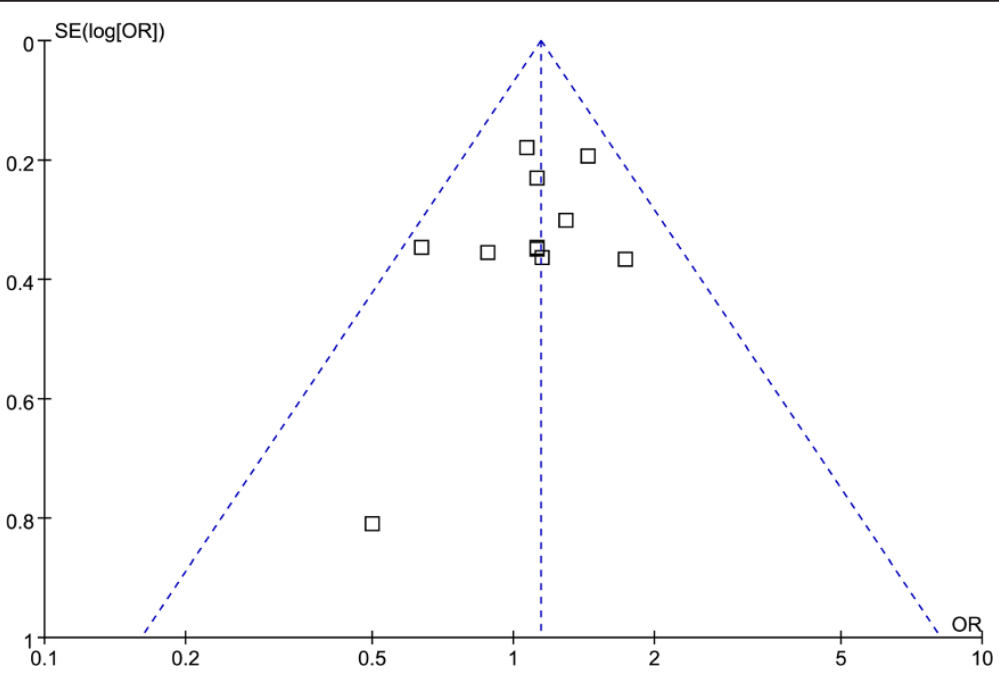

Figure 3 Funnel plot. This represents the publication bias test based on the ArgPro vs. ProPro genetic model. 
the measurement tools used. Second, statistical heterogeneity is substantial, although this is extremely common in meta-analyses of genetic association studies. We therefore performed subgroup analyses to consider the factors that may have contributed to the high degree of heterogeneity. Third, our included studies lacked comprehensive genotype information so the results of our meta-analysis were analyzed using unadjusted data; hence, we could not generate a more accurate analysis based on other adjusted factors. Finally, the sample size of our meta-analysis is relatively small and studies published in languages other than Chinese and English were not considered for inclusion.

\section{Conclusions}

Our meta-analysis showed a lack of association between the TP53 codon 72 polymorphism and OSCC susceptibility in Asians, although subgroup analysis demonstrated an association between the polymorphism and HPV-related OSCC patients. Because of the numerous limitations of this meta-analysis including small sample size and substantial statistical heterogeneity, our results should be interpreted with caution and further data from high-quality, well-conducted clinical studies of adequate statistical power are needed.

\section{Abbreviations}

Arg: Arginine; Cl: Confidence interval; HPV: Human papillomavirus; HWE: Hardy-Weinberg Equilibrium; OR: Odds ratio; OSCC: Oral squamous cell carcinoma; PCR: Polymerase chain reaction; PRISMA: Preferred Reporting Items for Systematic Reviews and Meta-Analyses; Pro: Proline; RFLP: Restriction fragment length polymorphism; SSCP: Single strand conformation polymorphism; TP53: Tumor protein p53.

\section{Competing interests}

The authors declare that they have no competing interests.

\section{Authors' contributions}

XTZ and YMN extracted the data and wrote the manuscript. WL and PLG performed statistical analysis. XTZ and WL carried out the systematic literature search and data collection. YG and WDL reviewed the manuscript. All authors approved the final manuscript.

\section{Acknowledgments \\ This research was supported (in part) by the Nature Science Foundation of Hubei Province (2012FFB03902) and the Natural Science Foundation of Hubei Ministry of Education (D20122405), without commercial or not-for-profit sectors. The funders had no role in study design, data collection and analysis, decision to publish, or preparation of the manuscript. No additional external funding was obtained for this study. We thank the Essaystar Group (http:/essaystar.com/), the Edanz (www.edanzediting.com/bmc1), and Joey S.W. Kwong (Division of Cardiology, Department of Medicine and Therapeutics, Prince of Wales Hospital, The Chinese University of Hong Kong, Shatin, Hong Kong) for assistance. We also wish to thank relevant editors and peer-reviewers for their hard work and suggestions.}

\section{Author details}

'Department of Stomatology and Center for Evidence-Based Medicine and Clinical Research, Taihe Hospital, Hubei University of Medicine, Shiyan 442000, P.R. China. Institute and Department of Stomatology, Chinese PLA General Hospital, Beijing 100853, P.R. China. ${ }^{3}$ Department of Oncology, Chinese PLA General Hospital, Beijing 100853, P.R. China. ${ }^{4}$ Department of Epidemiology, School of Public Health, Wuhan University, Wuhan 430071, P.R. China.
Received: 16 January 2014 Accepted: 24 June 2014

Published: 26 June 2014

\section{References}

1. Warnakulasuriya S: Global epidemiology of oral and oropharyngeal cancer. Oral Oncol 2009, 45(4-5):309-316.

2. Ghani WM, Doss JG, Jamaluddin M, Kamaruzaman D, Zain RB: Oral Cancer Awareness and its Determinants among a Selected Malaysian Population. Asian Pac J Cancer Prev 2013, 14(3):1957-1963.

3. Brinkman BM, Wong DT: Disease mechanism and biomarkers of oral squamous cell carcinoma. Curr Opin Oncol 2006, 18(3):228-233.

4. Goot-Heah K, Kwai-Lin T, Froemming GR, Abraham MT, Nik Mohd Rosdy NM, Zain RB: Human papilloma virus 18 detection in oral squamous cell carcinoma and potentially malignant lesions using saliva samples. Asian Pac J Cancer Prev 2012, 13(12):6109-6113.

5. Xia LY, Zeng XT, Li C, Leng WD, Fan MW: Association between p53 Arg72Pro polymorphism and the risk of human papillomavirus-related head and neck squamous cell carcinoma: a meta-analysis. Asian Pac J Cancer Prev 2013, 14(10):6127-6130.

6. Niu YM, Shen M, Li H, Ni XB, Zhou J, Zeng XT, Leng WD, Wu MY: No association between MTHFR A1298C gene polymorphism and head and neck cancer risk: a meta-analysis based on 9,952 subjects. Asian Pac J Cancer Prev 2012, 13(8):3943-3947.

7. Niu Y, Hu Y, Wu M, Jiang F, Shen M, Tang C, Chen N: CYP2E1 Rsa I/Pst I polymorphism contributes to oral cancer susceptibility: a meta-analysis. Mol Biol Rep 2012, 39(1):607-612.

8. Taniyama Y, Takeuchi S, Kuroda Y: Genetic polymorphisms and oral cancer. J UOEH 2010, 32(3):221-236.

9. Tsui IF, Poh CF, Garnis C, Rosin MP, Zhang L, Lam WL: Multiple pathways in the FGF signaling network are frequently deregulated by gene amplification in oral dysplasias. Int J Cancer 2009, 125(9):2219-2228.

10. Ara S, Lee PS, Hansen MF, Saya H: Codon 72 polymorphism of the TP53 gene. Nucleic Acids Res 1990, 18(16):4961.

11. Zhou X, Gu Y, Zhang SL: Association between p53 codon 72 polymorphism and cervical cancer risk among Asians: a HuGE review and meta-analysis. Asian Pac J Cancer Prev 2012, 13(10):4909-4914.

12. Xu T, Xu ZC, Zou Q, Yu B, Huang XE: P53 Arg72Pro polymorphism and bladder cancer risk-meta-analysis evidence for a link in Asians but not Caucasians. Asian Pac J Cancer Prev 2012, 13(5):2349-2354.

13. Zhuo XL, Cai L, Xiang ZL, Zhuo WL, Wang Y, Zhang XY: TP53 codon 72 polymorphism contributes to nasopharyngeal cancer susceptibility: a meta-analysis. Arch Med Res 2009, 40(4):299-305.

14. Zhuo XL, Li Q, Zhou Y, Cai L, Xiang ZL, Yuan W, Zhang XY: Study on TP53 codon 72 polymorphisms with oral carcinoma susceptibility. Arch Med Res 2009, 40(7):625-634.

15. Jiang N, Pan J, Wang L, Duan YZ: No significant association between $p 53$ codon $72 \mathrm{Arg} /$ Pro polymorphism and risk of oral cancer. Tumour Biol 2013, 34(1):587-596.

16. Moher D, Liberati A, Tetzlaff J, Altman DG, Group P: Preferred reporting items for systematic reviews and meta-analyses: the PRISMA statement. BMJ 2009, 339:b2535.

17. Salanti G, Amountza G, Ntzani EE, loannidis JP: Hardy-Weinberg equilibrium in genetic association studies: an empirical evaluation of reporting, deviations, and power. Eur J Hum Genet 2005, 13(7):840-848.

18. Huedo-Medina TB, Sanchez-Meca J, Marin-Martinez F, Botella J: Assessing heterogeneity in meta-analysis: Q statistic or 12 index? Psychol Methods 2006, 11(2):193-206.

19. Tandle AT, Sanghvi V, Saranath D: Determination of p53 genotypes in oral cancer patients from India. Br J Cancer 2001, 84(6):739-742.

20. Nagpal JK, Patnaik S, Das BR: Prevalence of high-risk human papilloma virus types and its association with P53 codon 72 polymorphism in tobacco addicted oral squamous cell carcinoma (OSCC) patients of Eastern India. Int I Cancer 2002, 97(5):649-653.

21. Kietthubthew S, Sriplung H, Au WW, Ishida T: The p53 codon 72 polymorphism and risk of oral cancer in Southern Thailand. Asian Pac J Cancer Prev 2003, 4(3):209-214.

22. Hsieh LL, Huang TH, Chen IH, Liao CT, Wang HM, Lai CH, Liou SH, Chang JT, Cheng AJ: p53 polymorphisms associated with mutations in and loss of heterozygosity of the $\mathrm{p} 53$ gene in male oral squamous cell carcinomas in Taiwan. Br J Cancer 2005, 92(1):30-35. 
23. Bau DT, Tsai MH, Lo YL, Hsu CM, Tsai Y, Lee CC, Tsai FJ: Association of p53 and p21(CDKN1A/WAF1/CIP1) polymorphisms with oral cancer in Taiwan patients. Anticancer Res 2007, 27(3B):1559-1564.

24. Kuroda Y, Nakao H, Ikemura K, Katoh T: Association between the TP53 codon72 polymorphism and oral cancer risk and prognosis. Oral Oncol 2007, 43(10):1043-1048.

25. Lin YC, Huang HI, Wang LH, Tsai CC, Lung O, Dai CY, Yu ML, Ho CK, Chen $\mathrm{CH}$ : Polymorphisms of COX-2-765G > C and p53 codon 72 and risks of oral squamous cell carcinoma in a Taiwan population. Oral Oncol 2008, 44(8):798-804.

26. Tu HF, Chen HW, Kao SY, Lin SC, Liu CJ, Chang KW: MDM2 SNP 309 and p53 codon 72 polymorphisms are associated with the outcome of oral carcinoma patients receiving postoperative irradiation. Radiother Oncol 2008, 87(2):243-252.

27. Misra C, Majumder M, Bajaj S, Ghosh S, Roy B, Roychoudhury S: Polymorphisms at p53, p73, and MDM2 loci modulate the risk of tobacco associated leukoplakia and oral cancer. Mol Carcinog 2009, 48(9):790-800.

28. Saini R, Tang TH, Zain RB, Cheong SC, Musa Kl, Saini D, Ismail AR, Abraham MT, Mustafa WM, Santhanam J: Significant association of high-risk human papillomavirus (HPV) but not of p53 polymorphisms with oral squamous cell carcinomas in Malaysia. J Cancer Res Clin Oncol 2011, 137(2):311-320.

29. Saleem S, Azhar A, Hameed A, Khan MA, Abbasi ZA, Qureshi NR, Ajmal M: P53 (Pro72Arg) polymorphism associated with the risk of oral squamous cell carcinoma in gutka, niswar and manpuri addicted patients of Pakistan. Oral Oncol 2013, 49(8):818-823.

30. Hollstein M, Sidransky D, Vogelstein B, Harris CC: p53 mutations in human cancers. Science 1991, 253(5015):49-53.

31. Sousa $H$, Santos AM, Pinto D, Medeiros R: Is the p53 codon 72 polymorphism a key biomarker for cervical cancer development? A meta-analysis review within European populations. Int I Mol Med 2007, 20(5):731-741.

32. Matakidou A, Eisen T, Houlston RS: TP53 polymorphisms and lung cancer risk: a systematic review and meta-analysis. Mutagenesis 2003, 18(4):377-385.

33. Zhou Y, Li N, Zhuang W, Liu GJ, Wu TX, Yao X, Du L, Wei ML, Wu XT: P53 codon 72 polymorphism and gastric cancer: a meta-analysis of the literature. Int J Cancer 2007, 121(7):1481-1486.

34. Kreimer AR, Clifford GM, Boyle P, Franceschi S: Human papillomavirus types in head and neck squamous cell carcinomas worldwide: a systematic review. Cancer Epidemiol Biomarkers Prev 2005, 14(2):467-475.

35. Heah KG, Hassan Ml, Huat SC: p53 Expression as a marker of microinvasion in oral squamous cell carcinoma. Asian Pac J Cancer Prev 2011, 12(4):1017-1022.

\section{doi:10.1186/1471-2407-14-469}

Cite this article as: Zeng et al: Association between the TP53 codon 72 polymorphism and risk of oral squamous cell carcinoma in Asians: a meta-analysis. BMC Cancer 2014 14:469.

\section{Submit your next manuscript to BioMed Central and take full advantage of:}

- Convenient online submission

- Thorough peer review

- No space constraints or color figure charges

- Immediate publication on acceptance

- Inclusion in PubMed, CAS, Scopus and Google Scholar

- Research which is freely available for redistribution

Submit your manuscript at www.biomedcentral.com/submit
() Biomed Central 